\title{
A BASELINE STUDY OF BRYOPHYTES AND AIR QUALTTY IN THE THEODORE ROOSEVELT NATIONAL PARK
}

\author{
David E. Bilderback \\ Department of Botany \\ University of Montana \\ Missoula
}

\section{Objectives}

The objectives of the research are threefold. The first objective is to prepare a moss flora by collecting, identifying and preparing herbarium specimens of taxa collected from all distinctive habitats of the three units of Theodore Roosevelt National Park. The second objective is to survey the prepared moss flora for $\mathrm{SO}_{2}$-sensitive species, and the third is to select species of mosses for elemental analysis.

\section{Methods}

To address the first objective, all habitat types of the North Unit of the Park were visited from 30 June to 4 July 1986, and bryophytes were collected at 19 locations. From 5 July to 9 July 1986 and 27 July to 2 August 1986, all habitat types of the South Unit and the Elkhorn Ranch Unit were visited and bryophytes were collected at 40 locations. Bryophytes from six additional locations in the South Unit of the Park were collected during 24-29 August 1986. Identification of the collected bryophytes and preparation of the herbarium collection has begun.

For the second objective, literature related to the effects of $\mathrm{SO}_{2}$ on mosses is being collected.

To achieve the third objective, nine samples of the moss Thuidium abiethinum were collected from a site in the Lone Butte oilfield, three sites in the North Unit of the Park, and five sites in the South Unit of the Park for sulfur and elemental analysis. Extraneous plant materials (juniper twigs and berries, and grass), as well as soil, were removed from each sample. The living green portion of the moss was separated from the partially decaying brown portion. Both portions of each of the 81 samples were oven-dried and ground. The samples have been randomized, and sulfur analyses will be determined by random order to reduce indeterminate error. Samples are being prepared for shipment to an analytical laboratory for elemental determination. 